Supporting Information

\title{
Chelation Effect in Polymerization of Cyclic Esters by Metal Alkoxides: Structure Characterization of Intermediate Formed by Primary Insertion of Lactide into the Al-OR Bond of Organometallic Initiator
}

\author{
Janusz Lewiński, ${ }^{\dagger, *}$ Paweł Horeglad, ${ }^{\dagger}$ Katarzyna Wójcik ${ }^{\dagger}$ and Iwona Justyniak ${ }^{\ddagger}$ \\ ${ }^{\dagger}$ Department of Chemistry, Warsaw University of Technology, Noakowskiego 3, 00-664, Warsaw, Poland \\ ${ }^{\dagger}$ Institute of Physical Chemistry, Polish Academy of Sciences, Kasprzaka 44/52, 01-224, Warsaw, Poland
}

Polymerization of $\varepsilon$-caprolactone with $1 \mathrm{a}$

The MALDI-TOF spectrum of the resulting polycaprolactone revealed two sets of signals (Figure 1S). The main distribution (difference between peaks $=114 \mathrm{Da}$ ) represents polycaprolactone chain of end group of 75 Da corresponding to $\mathrm{H}\left[\mathrm{O}\left(\mathrm{CH}_{2}\right)_{5} \mathrm{C}(\mathrm{O})\right]_{\mathrm{n}} \mathrm{OCH}_{2} \mathrm{CH}_{2} \mathrm{OCH}_{3}(114.14 * \mathrm{n}+76 \mathrm{Da})$. The difference between observed mass of end group (75 Da) and calculated for $\mathrm{H} \sim \mathrm{OCH}_{2} \mathrm{CH}_{2} \mathrm{OCH}_{3}(76 \mathrm{Da}$ ) is only $1 \mathrm{Da}$ and lies within the range of experimental error. The second (differnce between peaks = $114 \mathrm{Da}$ ) distribution represents polycaprolactone chains of end group of $113-0 \mathrm{Da}$, which represents cyclic policaprolactone oligomers. (The mass of each peak constitutes of polymer chain mass + sodium cation mass of $23 \mathrm{Da}$ ).

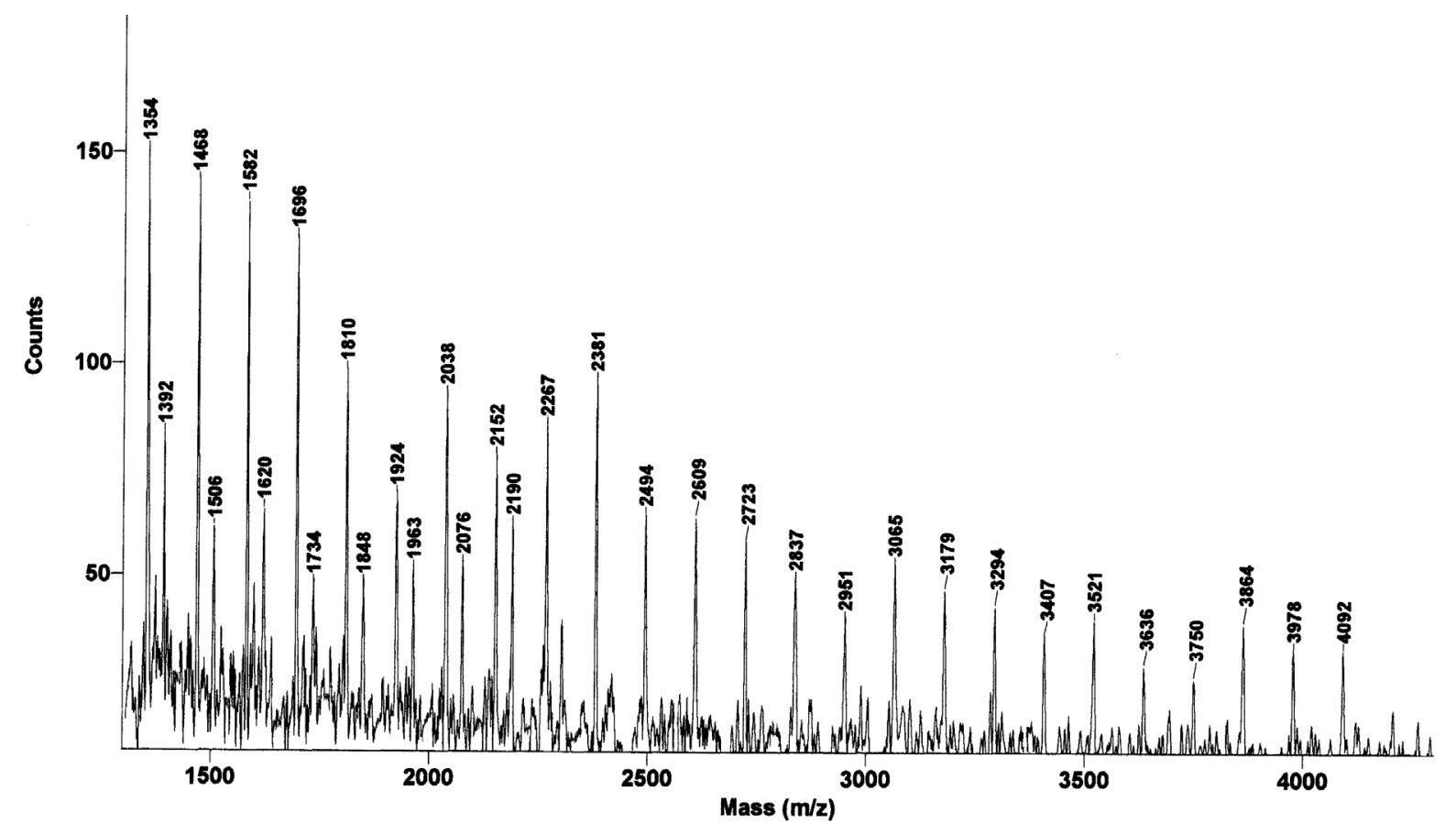

Figure 1S. Polycaprolactone obtained with 1a as the initiator.

(1-LA) ${ }^{1}$ H NMR spectrum 


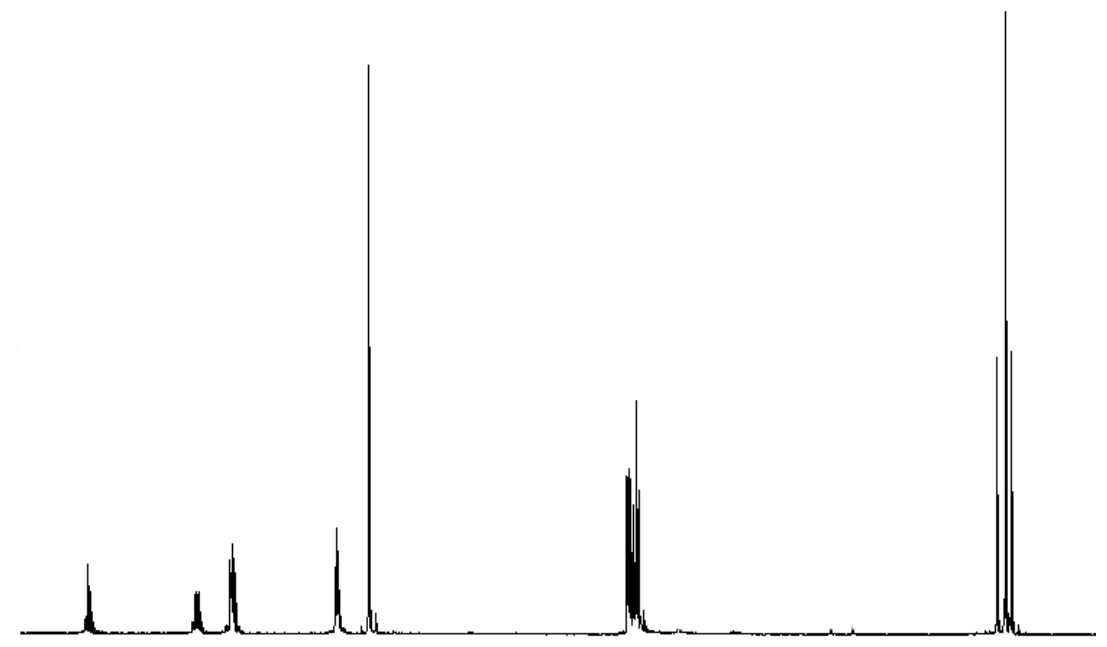

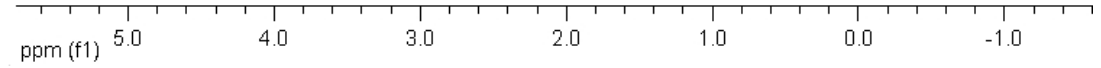

Figure 2S. The ${ }^{1} \mathrm{H}$ NMR spectrum of 1-LA $\left(\mathrm{CDCl}_{3}, 20^{\circ} \mathrm{C}\right)$. 